Mina Isotani

RESUMO: Narrativas da América - Amerika Monogatari de Nagai Kafû é um livro que contém vinte e três narrativas escritas no período de 1903 a 1907, época em que o escritor morou nos Estados Unidos. Esta obra ilustra a reflexão do autor sobre temas como a imigração japonesa no início do século XX, o encontro com a cultura ocidental e a sociedade nipônica pós Revolução Meiji.

E na presente sessão de "Estudos de Pós-Graduação" será feita uma breve apresentação dos resultados obtidos durante o período de pesquisa para a realização da dissertação de mestrado intitulada Narrativas da América: $O$ Confronto com o Desconhecido.

PALAVRAS-CHAVE: Nagai Kafû, literatura japonesa, literatura de viagem e imigração japonesa.

ABSTRACT: Nagai Kafu's Amerika Monogatari is a book that contains twenty-three narratives written in the period from 1903 to 1907, time in that the writer lived in the United States. This work illustrates the author's reflection on themes as the Japanese immigration at the beginning of the XX century, the encounter with the western culture and the Japanese society after the Meiji Revolution.

In the present session of "Post Graduate Studies" it will be made one brief presentation of the results gotten during the period of research for the accomplishment of the dissertation entitled Narratives of America: The Confrontation with the Stranger.

KEYWORDS: Nagai Kafû, japanese literature, travel literature and japanese immigration. 
A leitura é um momento de descoberta e reflexão de contextos culturais diversos, que podem levar à reavaliação dos conceitos em relação à sociedade. Os relatos de viagem estão entre os registros desse tipo de impacto com o novo, com as expectativas, com o inesperado.

Assim, quando o olhar do viajante se volta para o outro, seu olhar crítico cria uma relação que pode ir da veneração à ojeriza - dependendo desta, a relação que o viajante irá desenvolver com o não-familiar pode ser de comparação - o que vai aumentar seu envolvimento e fusão na cultura alheia - ou de julgamento - que resultará na reafirmação dos próprios valores culturais.

Nagai Kafû foi um desses viajantes que relatou o caminho percorrido, captando através do deslocamento físico, momentos e experiências vividas pelos imigrantes japoneses, que foram aos Estados Unidos no início do século XX.

E foram os olhos desse escritor japonês, que nos guiaram para dentro das mais diversas histórias e nos deixaram penetrar em um mundo às vezes real e outras vezes fictício, de uma realidade desconhecida pela própria sociedade japonesa da época. A obra Amerika Monogatari / Narrativas da América é o resultado da compilação desses relatos e ensaios escritos durante os quatro anos da estada de Kafû nos Estados Unidos.

E foi através de narrativas que contam a vivência dos imigrantes japoneses que Nagai Kafû oferece-nos não apenas a experiência de conhecer a realidade de um povo, mas também a de refletir sobre questões como o comportamento humano diante da loucura, religião e valores sociais.

Assim, a dissertação intitulada Narrativas da América: $O$ Confronto com o Desconhecido teve como intuito tornar acessível a outros leitores essa reprodução sensível da paisagem dos Estados Unidos, da sociedade americana e dos sentimentos resultantes do encontro com o ocidente do próprio Kafû. Para tanto, o trabalho foi subdividido em três partes: A primeira consiste da exposição de dados biográficos e os trabalhos realizados por Nagai Kafû. A segunda parte refere-se à reflexão quanto aos temas abordados nas narrativas. E a última a tradução completa do livro Narrativas da América.

O presente artigo apresenta a suma dessa dissertação em quatro itens: 1 . Narrativas da América; 2. Temas principais; 3. A Tradução de Narrativas da América; 4. Considerações Finais.

\section{Narrativas da América}

Durante o período de quatro anos em que viveu nos Estados Unidos (1903-1907), Kafû escreveu quatorze narrativas, dez ensaios e cerca de sete cartas. Apesar de ter escrito enquanto estava na América, quatorze trabalhos foram publicados no Japão. Um mês após 
ter retornado ao seu país, em agosto de 1908, foram compiladas vinte narrativas e publicadas em um livro intitulado Narrativas da América. E devido à exposição sensível e perspícua sobre as observações feitas a propósito de um país e de um povo desconhecido, somado a apreciação da cultura e literatura ocidental, Narrativas da América foi considerado como uma obra única, que conseguiu descrever minuciosamente os Estados Unidos.

O volume reeditado por Kafû anos mais tarde aparece com uma narrativa a mais Névoa Noturna - e, após sua morte, o editor acrescentou outra história - Uma Noite no porto de Seattle, que também havia sido escrita enquanto estava nos Estados Unidos.

Deste modo, nas publicações atuais do livro encontramos vinte e três narrativas:

1. キャビン夜話 - Conversa Noturna numa Cabine

2. 野路のかえり Caminho dos Prados

3. 岡の上-Acima da Colina

4. 酔美人 - Beleza Inebriante

5. 長髪 - Cabelos Compridos

6. 春と秋 Primavera e Outono

7. 雪のやどり Abrigo da Neve

8. 林間-No Bosque

9. 悪友-Má Companhia

10. 旧恨 - Velhos Pesares

11. 寝覚め-Despertar

12. 夜の女 - Damas da Noite

13. 一月一日 - Primeiro de Janeiro

14. 暁- Alvorada

15. シカジの二日 - Duas Noites em Chicago

16. 夏の海 - Mar de Verão

17 夜半の酒場- O Bar da Madrugada

18. 落ち葉 - Folhas Caídas

19. 支那街の記 - Conto de um Bairro Chinês

20. 夜歩き-Passeio Noturno

21. 六月の夜の夢 - Sonho de uma Noite de Junho

22. シアトルの一夜 Uma Noite no Porto de Seattle

23. 夜の霧 - Névoa Noturna 
As narrativas desta obra têm como cenário a região de Seattle e Tacoma e tratam principalmente de imigrantes japoneses nos Estados Unidos. Em Conversa Noturna numa Cabine, por exemplo, que abre Narrativas da América, Kafû traz dois jovens japoneses que estão a caminho dos Estados Unidos. Um deles deixara o país por estar cansado dos valores sociais prevalecentes, que não o consideravam digno de se casar com a mulher amada; o outro estava esperançoso de que, enquanto estivesse nos Estados Unidos, teria muitas oportunidades de estudo, já que estava desacreditado em sua terra natal. Através das narrativas, Kafû vai registrando a vida dos imigrantes japoneses, que na época somavam cerca de cem mil pessoas e que se viam diante de inúmeros problemas como a discriminação racial, a difícil adaptação e as doenças. A maior parte deles trabalhava no campo, outros administravam restaurantes abandonados, dirigiam barracas de diversão na Ilha de Coney ou eram adeptos de jogos de azar.

A publicação desse livro causou impacto no meio literário japonês, pois o estilo e a estrutura diferiam dos trabalhos naturalistas de Emile Zola, que dominavam o meio literário do momento. Além disso, Narrativas da América foi o primeiro livro que retratou observações e informações da vida e da cultura nos Estados Unidos. E até os dias de hoje essa obra é mencionada como a única que conseguiu descrever, com caráter íntimo e detalhista, o mundo - a América do qual tanto comentavam na época.

Uma das razões pelas quais esse livro foi bem recebido pelo publico japonês foi justamente a mudança de estilo e técnica de escrita. Como todas as tendências literárias do ocidente chegaram num curto espaço de tempo era de se esperar que os movimentos literários como o Naturalismo não chegassem com a mesma força, impacto e carga significativa como aconteceu na França. Assim, o Naturalismo japonês seguiu a linha autobiográfica, criticada pelos estudiosos por sua monotonia. Kafû imprimiu um tom completamente diferente em Narrativas da América. Contudo, foi criticado por deixar de lado a descrição da vida real, passando a relatar narrativas ficcionais, cuja orientação diferia da pregada pelo Naturalismo.

\section{Temas Principais}

O livro Narrativas da América é o resultado da compilação de várias narrativas escritas durante o período em que o autor viveu nos Estados Unidos. São ensaios e relatos escritos de acordo com as experiências vivenciadas pelo autor e conforme as histórias que ouvia de outras pessoas. Por isso, a temática de cada narrativa também vai seguir o caminho de Kafû pela terra estrangeira.

Isso possibilitou que o leitor acompanhasse o amadurecimento de Kafû como escritor e também mostrou o caminho percorrido, de Nova York a Kalamazoo. Assim, é possível destacar a mudança estilística ao trabalhar e construir o enredo, que no início caracteriza-se 
pela forte influência naturalista, como observamos em $O$ Caminho do Prados e que depois o escritor passou a trabalhar de forma mais livre, criando um universo de personagens e enredo desconectados da idéia de hereditariedade e meio ambiente como fator delimitador.

Apesar das narrativas não terem sido publicadas na ordem cronológica em que foram escritas, podemos percorrer o trajeto feito pelo autor, o que viu e observou em cada lugar e, principalmente, sua empreitada para angariar fundos para ir à França.

Fica evidente também que as narrativas não são resultado de um livro de temáticas pré-estabelecidas e sim, conforme a inspiração, as angústias, conquistas e visões diante do mundo em que vivia, a leitura desse livro transporta o leitor por Nova York, Chicago, Illinois, pelos bordéis, pelas áreas pobres das grandes cidades, entre outros lugares. Enfim, aproxima o leitor de um mundo desconhecido e o faz se sentir íntimo dessa viagem, incorporando as vivências de Kafû como suas.

Podemos dizer que o escritor japonês foi um viajante que observou e adentrou no quotidiano das cidades, retirando desse espaço urbano a representação da beleza citadina. Ainda, utilizando o termo de Charles Baudelaire, Kafû seria o flâneur, o observador solitário perdido no meio da multidão e "a embriaguez na qual o flâneur se abandona é a da mercadoria levada pela torrente dos fregueses" (BENJAMIN, 1989, 129). Isto é, a não identificação entre o seu "eu" e o mercado, esse indivíduo aproxima-se, num envolvimento de empatia, com a mercadoria.

Em Narrativas da América, Kafû trabalha com diversos temas como a religião, as mulheres, o relacionamento entre o homem e a mulher, a condição precária e a ambição dos imigrantes japoneses, o mundo dos prazeres e a sua perspectiva dos Estados Unidos e seu povo. A seguir, serão destacados alguns desses principais temas e reflexões serão realizados sobre cada um deles com o objetivo de mostrar o choque cultural entre a cultura japonesa e a cultura americana e a vida dos imigrantes japoneses.

\section{A Tradução de Narrativas da América}

A tradução apresentada na dissertação foi baseada na última versão modificada do livro Narrativas da América, publicado pela editora Iwanami no dia quatorze de abril de 2006. São vinte e uma narrativas, que foram publicadas na primeira compilação em agosto de 1908 e Uma Noite no Porto de Seattle e Névoa Noturna que foram inseridas após a morte de Nagai Kafû.

O estilo de escrita do autor inclui sentenças extremamente longas e muitas vezes, as orações apresentam-se intercaladas, criando certa descontinuidade na leitura. Em alguns casos, um único parágrafo chega a seguir por vinte linhas e para separar as idéias diferentes dentro da mesma frase, Kafû utiliza as reticências e o travessão com freqüência. 
A nova versão do livro contém, além das modificações feitas anteriormente pelo próprio autor, a leitura de ideogramas antigos, nomes de cidades, países, entre outros.

$\mathrm{Na}$ tradução, mantivemos o mais fiel possível da versão original, sendo feitas apenas pequenas modificações, principalmente de pontuação, devido às frases longas. Palavras em inglês utilizadas pelo autor para dar ênfase ao momento e que, perderiam a força com a tradução para a língua portuguesa, assim como, termos japoneses, referentes a comidas ou brincadeiras típicas, desconhecida daqueles que não conhecem a cultura japonesa, foram citadas nas notas de rodapé. As anotações feitas entre parêntese no corpo do texto são esclarecimentos do próprio autor.

Os poemas franceses cotejados e traduzidos para o japonês por Kafû foram traduzidos literalmente para o Português. Nesse caso, foi feita a tradução disponibilizada pelo próprio Kafû e não foi levado em conta qualquer erro de tradução que possa ter sido cometido pelo autor.

As dificuldades de transpor a estilística do escritor para a língua portuguesa foram imensas. Se a tradução é a arte de reescrever uma obra sem que esta perca sua identidade estilística e de conteúdo, esta tradução foi resultado desse esforço de repassar ao público, de forma fiel, as narrativas de Nagai Kafû, que não só descreveu a vida de seus conterrâneos imigrantes, mas acabou por descrever as várias facetas que o próprio ser humano acaba por revelar diante de determinadas circunstâncias.

\section{Considerações Finais}

Narrativas da América foi o resultado do olhar apurado de Nagai Kafû, a exemplo de um observador flâneur das poesias de Charles Baudelaire, que "perambula pelas passagens, embriagado pela multidão produtiva" (MURICY, 1987, p.501) e encontra beleza nas luzes da cidade e na boêmia, com o intuito de mostrar a poética da vida moderna nas metrópoles. Esse olhar adentrou o mundo da periferia, onde deparou com a prostituição, a discriminação de raças e de classe social, a pobreza, a sujeira e o quotidiano noturno. Esse observador foi além e também expôs a contemplação da cultura americana, através de contrastes e situações opostas à cultura japonesa, como a organização familiar e o relacionamento entre o homem e a mulher. E como em Les fenêtres ou A Janela, em que Baudelaire reflete sobre a maneira como essas observações são realizadas:

Celui qui regard Du dehors à travers une fenêtre ouverte, ne voit jamais autant de choses que celui qui regarde une fenêtre fermée. Il n'est pás d'objet plus profond, plus mystérieux, plus fécond, plus ténébreux, plus ébloissant qu'une fenêtre éclairée d'une chandelle.'

1. BAUDELAIRE, Charles. Modemismo: guia geral 1890-1930. São Paulo: Companhia das Letras, 1989, p. 276. 
(Quem olha de fora por uma janela aberta nunca vê tantas coisas quanto aquele que olha uma janela fechada. Não existe coisa mais profunda, mais misteriosa, mais fecunda, mais tenebrosa, mais fascinante do que uma janela alumiada por uma vela). ${ }^{2}$

Isto é, em cada uma das narrativas o narrador concentrou seu olhar num único tema, dissecando-o para expor o assunto de maneira detalhada, atraindo a atenção do leitor com ensaios e relatos sobre o comportamento dos indivíduos, diante das dificuldades causadas pelas mudanças econômicas e sociais do final do século XIX. Georg Lukács diz que é exatamente essa "(...) riqueza e variedade de cores, variabilidade e multiplicidade de aspectos da experiência humana" (LUKÁKS, 1965, p. 52) que atrai o interesse dos leitores. E Kafû isolou-se da multidão para mostrar essa beleza que há por trás do que é considerado comum e ordinário e investigou essas unidades ignoradas pelo observador comum para expor outro ponto de vista. Ou seja, esse viajante transpõe os limites dos valores e do pré-julgamento e vai mais além "(...) na medida em que surgem brechas na evidência, abrindo passagens na paisagem ou contornando desníveis e vazios" (CARDOSO, 1995, p.359)

Ao seguir o olhar desse viajante, percebe-se que revela o impacto com odesconhecido ao encontrar paisagens diversas durante o caminho percorrido, onde o deslocamento e os cenários descontínuos causaram o estranhamento, impulsionando a reflexão não apenas do panorama, mas também sobre a existência de sociedades diferentes da sua.

Assim, Narrativas da América é uma obra que atrai a atenção por seu tom evocativo, pelo estilo de prosa e pela forma intimista com que as narrativas são descritas. Também é o produto do choque cultural vivenciado por Nagai Kafû nos Estados Unidos e a maneira como essa experiência o afetou como escritor e como um homem Japonês. Apesar de não ter como objetivo a crítica à sociedade japonesa ou americana, grifou com extrema sensibilidade o encontro com uma civilização completamente diversa da sua. Descreveu com lucidez o impacto do ocidente no Japão e na vida dos imigrantes japoneses, expondo seus sentimentos, observações e apreciação da cultura e literatura ocidental.

Segundo o crítico japonês Sôma Gyôfu o estilo de escrita de Kafû constituiu uma nova forma de expressão literária da sensibilidade e das sensações.

"Os Estados Unidos foram retratados por um ângulo completamente diferente daqueles apresentados até agora. Só isso já o torna uma obra ímpar. Contudo, o que me comoveu mais foi a forma inédita com que o escritor expressou a sensibilidade e as sensações. Quando li Narrativas da América, senti que surgira um mundo com

2. Tradução do trecho de Les fenêtres In. Modernismo: guia geral 1890-1930. São Paulo: Companhia das Letras, 1989, p. 276. 
novas emoções e sensações. Percebi que, mesmo em língua japonesa, era possível escrever esse tipo de literatura."

Kafû observou a sociedade americana com o olhar do "outro", com a percepção mais aguçada e conseguiu reproduzi-la de forma nítida. As narrativas não expressam críticas sobre a rápida modernização do Japão ou quanto à periferia das cidades americanas, mas mostram o olhar estrangeiro que "(...) é capaz de ver aquilo que os que lá estão não podem mais perceber"(PEIXOTO, 1995, p. 363). E o intenso movimento das cidades e as mudanças econômicas e sociais causam certa superficialização do olhar, que tende a ver apenas os elementos externos e vimos que Nagai Kafû fez o oposto ao fixar suas contemplações em certos pontos para mostrar todos os aspectos das cidades americanas, com seus bordéis, seus cenários campestres, seus enormes prédios ou luzes multicores.

Portanto, as reflexões deste trabalho foram realizadas com o intuito de apresentar esse escritor ainda desconhecido no Brasil e tratar acerca do encontro do viajante com as mais diversas situações durante sua jornada, resultando numa obra que apresenta os Estados Unidos aos japoneses; Acompanham-se também o amadurecimento literário do escritor e, principalmente, apresenta-se uma nova maneira de enxergar os mais variados tipos de beleza encontrados nas periferias pobres ou nos campos e novas formas de pensar em relação ao comportamento humano diante de situações adversas. O Homem constrói, apreende e interpreta a realidade a partir dos instrumentos que lhe são fornecidos pela cultura, como um tecelão quase compulsivo de si próprio, bordando sem cessar teias de significados para dar sentido ao mundo. E se essas teias, onde se misturam pontos abertos e fechados, novos e antigos, e linhas de todas as cores, formam a cultura é a partir desse véu da cultura, dessas lentes, que Narrativas da América também nos auxilia a compreender os valores da época, a sociedade americana e, ainda nos faz refletir sobre nós mesmos e a forma como enxergamos o mundo.

3. Tradução adaptada da crítica de Sôma Gyôfu, retirada do site: http://uraaozora.jpn.org/nagai.html Trecho no idioma original: 而もそのアメリカと云ふ異国を今迄多樊の人が好加減なうはつ面だけ の紹介をして居たのと、全く異つた方面から描いてある。それだけでも非常に珍らしかつた。併 し僕が何よりも先づ嬉しく感じたのは、作者の情緒の新らしさと、感覚の新らしさとであつた。 『あめりか物語』を読んだ時僕自身にも何だか情緒と感覚の新らしい世界が開けたやうな気がし た。日本語でもこんな文学が出来るのかと云ふやうな気がした。 
ABDALA, Jr. Benjamin. Introdução à análise da narrativa. São Paulo: Editora Scipione, 1995.

AUERBACH, Eric. "A meia marrom" In: Mimesis: a representação da realidade na literatura ocidental. São Paulo: Editora Perspectiva, 1971.

BAKHTIN, Mikhail. Estética da Criação Verbal. São Paulo: Editora Martins Fontes, 2003.

Questões de Literatura e de Estética: a teoria do romance. Trad. Aurora Fornoni Bernardini. São Paulo: UNESP, 1990.

BARTHES, Roland. Crítica e Verdade. São Paulo: Editora Perspectiva, 2003.

BENJAMIN, Walter. O narrador. In: Os Pensadores. São Paulo: Abril Cultural, 1980, p.5785.

"Charles Baudelaire: Um Lírico no Auge do Capitalismo" In: Obras Escolhidas. Volume III. São Paulo: Brasiliense, 1989.

Reflections: essays, aphorisms, autobiographical writings. New York: Schocken Books, 1986.

CÂNDIDO, Antonio. Brigada Ligeira e outros escritos. Assis: Editora UNESP, 1992.

"A Literatura e a Formação do Homem" In: Ciência e Cultura, v.24, no 9,1972, pp.05.

"A Personagem do Romance" In: A Personagem de Ficção. São Paulo: Perspectiva, 2007.

CARDOSO, Sérgio. "O Olhar do Viajante”. In: O Olhar. São Paulo: Companhia das Letras, 1995, pp. 347-360.

CARVALHO, Alfredo Leme Coelho de. Foco narrativo e fluxo da consciência: questões de teoria literária. São Paulo: Pioneira, 1981.

FRIEMAN, Norman. O Ponto de Vista na Ficção: o desenvolvimento de um conceito crítico. Trad. Fábio Fonseca de Melo. In: Revista USP. São Paulo: Editora USP, no. 53, março/maio 2002, pp.166-182.

FURST, Lilian R. e KRINE, Peter N. S. O Naturalismo. Trad. João Pinguelo. Lisboa: Editora Lysia, 1971.

HUTCHISON, Rachael. Occidentalism and critique of Meiji: the west in the returnee stories of Nagai Kafû. In: British, Japan Forum,13, Routledge, 2001, p.195-213.

HYDE, G. M. "A Poesia da Cidade" In: Modernismo: guia geral 1890-1930. São Paulo: Companhia das Letras, 1989.

ITO, Ken K. Visions of Desire: Tanizaki's Fictional Worlds. Stanford: Stanford University Press, 1991. 
JOUVE, Vincent. A leitura. São Paulo: Editora Unesp ,2002.pp.17.

KAFÛ, Nagai. Amerika Monogatari/ Narrativas da América. アメリカ物語. Tóquio: Gakushû Kenkyûsha, 1978.

KAFÛ, Nagai. Nagai Kafû-Gendai Nihon no Bungaku/Nagai Kafû (A literatura do Japão moderno). Tóquio: Gakushû Kenkyûsha. 1978 / 永井荷風 現代日本の文学、東京、 学習研究社、1978 年.

KEENE, Donald. "Nagai Kafü" In: Down to the West: Japanese Literature in the Modern Era. New York: Hewwyholt, 1984, pp. 386-437.

LAPLANTINE, François. Aprender Antropologia. São Paulo: Brasiliense, 1995

LEITE, Dante Moreira. Psicologia e Literatura. São Paulo: Companhia Editora Nacional, 1967.

LUKÁCS, Georg. Ensaios sobre Literatura. Rio de Janeiro: Editora Civilização Brasileira, 1965.

A Teoria do Romance. São Paulo: Editora 34, 2007.

MATSUMOTO, Hajime. As Mulheres de Kafû. Tóquio: Shiromizu, 1998.

MURICY, Katia. Benjamin: "Política e Paixão" In: Os Sentidos da Paixão. São Paulo: Companhia das Letras, 1987.

PEIXOTO, Nelson B. “O Olhar do Estrangeiro”. In. O Olhar. São Paulo: Companhia das Letras, 1995, pp. 361-367.

PONTIERI, Regina Lúcia. A Voragem do Olhar. São Paulo: Editora Perspectiva. Coleção Debates, 1988.

RIMER, J. Thomas. "Nagai Kafû and Mori Ôgai. The Past versus the Present". In: Modern Japanese Fiction and Its traditions, pp. 138-151. New Jersey: Princenton University, 1978. ROSENFELD, Anatol. "Literatura e Personagem" In: A Personagem de Ficção. São Paulo: Perspectiva, 2007.

SEIDENSTICHER, Edward. Kafû the Scribbler: The Life and Writing of Nagai Kafû, 18791959. Michingan: Center for Japanese Studies, 1990.

SNYDER, Stephen. Fictions of desire: Narrative form in the novels of Nagai Kafû. Honolulu: Hawaii, 2000.

SUENOBU, Yoshiharu. Os Estados Unidos Visto por Nagai Kafû. Tóquio: Chuo Koronsha, 1997.

TODOROV, Tzevetan. Nós e os Outros-A Reflexão Francesa sobre a Diversidade Humana 1.

Trad: Sergio Goes de Paula. Rio de Janeiro: Vozes, 1993 "As Categorias da Narrativa Literária" In: Análise Estrutural da Narrativa. Trad. Maria Pinto. Rio de Janeiro: Vozes, 1971, p.223.

WASHBURN, Dennis C. "Nostalgic Narratives: the primitivistic voice of Nagai Kafü" In: The Dilema of the Modern in Japanese Fiction. Londres: Yale University Press, 1995, pp.195-209. 